\title{
In-Situ Gel-Free Plasmid Reassembling for Rapid Gene Subcloning and Truncation
}

\author{
Narges Jamal-Livani ${ }^{1}$ \\ https://orcid.org/0000-0003-4069-1718 \\ Elham Nikokar ${ }^{1}$ \\ https://orcid.org/0000-0003-2896-0807
}

\author{
Yaghoub Safdari ${ }^{\star 2,3}$ \\ https://orcid.org/ 0000-0002-7515-2186
}

${ }^{1}$ Golestan University of Medical Sciences, School of advanced Technologies in Medicine, Department of Medical Biotechnology, Student Research Committee, Gorgan, Iran; ${ }^{2}$ Golestan University of Medical Sciences, Golestan Research Center of Gastroenterology and Hepatology, Gorgan, Iran; ${ }^{3}$ Golestan University of Medical Sciences, Medical Cellular and Molecular Research Center, Gorgan, Iran.

Received: 2019.05.13; Accepted: 2020.02.21.

${ }^{*}$ Correspondence: Safdari_14@yahoo.com; Tel: +98-17-32450995.

\section{HIGHLIGHTS}

- Two plasmids can be mixed and double-digested simultaneously

- DNA segment released from one plasmid can enter the other plasmid in the reaction

- A nucleotide sequence can be cut out from a plasmid by in-situ double digestion and ligation

Abstract: Gene subcloning, a process in which the nucleotide sequence of interest is excised from on plasmid and inserted into another, seems to be an easy task to done. However, not all subcloning attempts are successful, even when the insert sequence and the double digested target plasmid are successfully purified form agarose gel and thought to be ready for subsequent ligation. In the current study we introduce a reliable, easy, and time consuming method for gene subcloning and also truncation. The stages are all carried out in a single microtube without any running on a gel, making it possible to accomplish a successful gene subcloning or truncation even with low concentrations of DNA molecules. Summarily, subcloning is achieved by mixing the plasmids of interest in a microtube and subjecting to restriction enzymes whose restriction sites flank the segment that is going to be subcloned. Digestion mixture is precipitated in the same microtube using isopropanol and the resultant DNA molecules are allowed to take part in a ligation reaction. The recombinant plasmids of interest are screened by colony PCR. Truncation is achieved by doubledigestion of the plasmid of interest using a restriction enzyme whose restriction site flanks the segment that is going to be cut out.

Keywords: plasmid mixing; concurrent digestion; simultaneous ligation; gel-free subcloning.

\section{INTRODUCTION}

Restriction enzymes digest nucleotide sequences at specific restriction sites, making it possible to insert a gene of interest into a nucleotide sequence (e.g. genomic DNA, cloning or expression vectors) and produce a recombinant sequence. Digested DNA fragments are usually separated using electrophoresis in agarose gel, which then are purified from the gel either manually or by using commercially available kits. Large quantities of digested DNA molecules separated on the gel may be lost during gel purification steps, meaning 
that researchers need to repeat plasmid extraction, digestion, and purification stages if the concentrations of starting DNA molecules are insufficient for subsequent ligation. Insertion of a gene of interest into a plasmid requires successful digestion and ligation reactions. Ligation reaction is not always successful, even when the insert and the digested plasmid carry similar sticky ends. Several reasons (e.g. high salt or EDTA concentration in the reaction, high DNA concentration, impurities, and so forth) and solutions have been proposed when ligation is unsuccessful 1. However, the main cause of ligation failure sometimes remains elusive. We had severe trouble with inserting $\mathrm{Ncol} / \mathrm{Xhol}$ double-digested nucleotide sequence encoding for a scFv antibody into pET22b (+) expression vector double-digested with the same enzymes. Sometimes even, the extracted plasmids were resistant to enzymatic digestion. Methylation of restriction sites in plasmid within bacterium cytoplasm may be a reason why restriction enzymes are unable to digest the plasmid while it contains appropriate restriction sites 2,3. We did not consider methylation of restriction sites as a potential cause of plasmid digestion failure because bacterial Dam and Dcm methylases were unlikely at all to methylate nucleotides in the sticky ends of $\mathrm{Ncol} / \mathrm{Xhol}$ digested sequences 3,4 . UV radiation is also among the factors that interfere with DNA digestion and ligation 5,6. It usually takes both time and cost to discover what factor interferes with digestion and/or ligation reactions. So, we decided to set a gel-free protocol to bypass all potentially interfering factors in these reactions in order to simplify gene sub-cloning and truncation. In summary, gene subcloning is achieved by mixing cloning and expression vectors within a microtube and double-digested at the same time. After ligation of DNA molecules in the mixture, a third enzyme is used to digest non-recombinant expression vectors. For gene truncation, plasmid is double digested with a single enzyme and allowed to re-assemble.

\section{MATERIALS AND METHODS}

\section{Materials and reagents}

pGH cloning vector containing the gene of interest (single chain anti-EGFR antibody-encoding sequence) was purchased from Nedaye Fan (Tehran, Iran). pET22b(+) expression vector was purchased from Novagen (Cat. No. 69744-3). Forward and Reverse primers (5'- CACTATAGGGGAATTGTGAGCG-3' and 5'CTAGTTATTGCTCAGCGGTGG-3, respectively, synthesized by BioBasic Co. Canada) were designed based on $\mathrm{pET} 22 \mathrm{~b}(+)$ cloning site. $\mathrm{Ncol}$, Xhol, and Hind III restriction enzymes were purchased from Takara (Japan).

\section{Combination and simultaneous digestion of plasmid pair- the first round of digestion}

Simultaneous digestion of plasmids was carried out in a $0.5 \mathrm{~mL}$ microtube (total volume of $15 \mu \mathrm{L}$, Figure 1) containing $500 \mathrm{ng}(2.5 \mu \mathrm{L}) \mathrm{pGH}$ cloning vector, $200 \mathrm{ng}(1.5 \mu \mathrm{L}) \mathrm{pET} 22 \mathrm{~b}(+)$ expression, $5.5 \mu \mathrm{L}$ distilled water (DW), $1 \mu \mathrm{L} \mathrm{Ncol}(10 \mathrm{u}), 1 \mu \mathrm{L}$ Xhol $(10 \mathrm{u})$, and $3 \mu \mathrm{L}$ Tango buffer $10 \mathrm{X}$. After $1 \mathrm{~h}$ incubation at room temperature, the restriction enzymes were inactivated by incubation at $85^{\circ} \mathrm{C}$ for $15 \mathrm{~min}$. Digestion product (combination of digested plasmids) was precipitated in the same microtube by addition of $15 \mu \mathrm{L}$ isopropanol, $20 \mathrm{~min}$ incubation in refrigerator $\left(-20^{\circ} \mathrm{C}\right)$, and $10 \mathrm{~min}$ centrifugation at $10000 \mathrm{~g}$. The microtube was depleted and allowed to dry for $20 \mathrm{~min} .100 \mu \mathrm{L}$ ethanol $70 \%$ was added to the microtube and depleted again after 2 min centrifugation at $10000 \mathrm{~g}$. After complete evaporation of ethanol $70 \%, 10 \mu \mathrm{L} \mathrm{DW}$ was added to the microtube to dissolve the precipitated DNA molecules in $20 \mathrm{~min}$ at room temperature. 


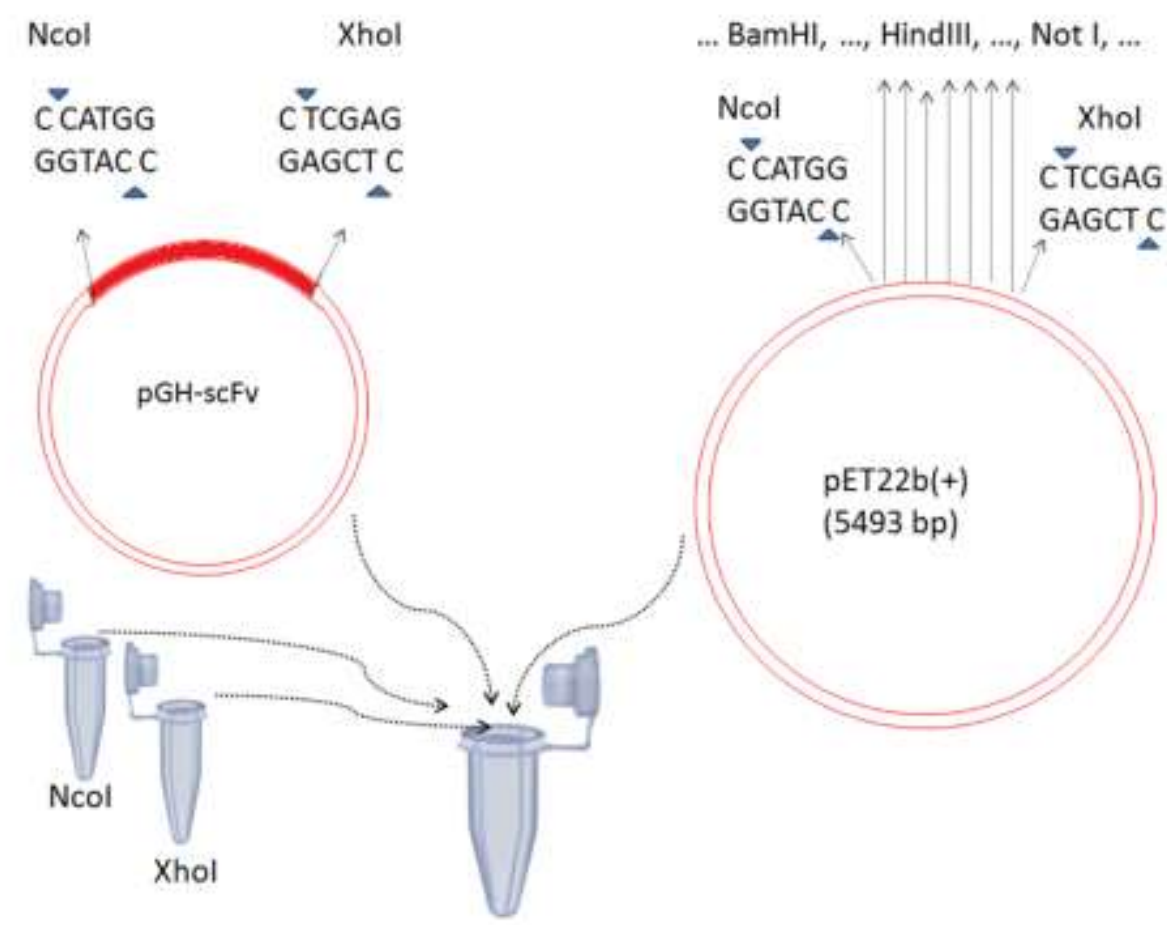

Figure 1. Schematic overview of simultaneous digestion of cloning and expression vectors. Both plasmids in company with both restriction enzymes ( $\mathrm{Ncol}$ and $\mathrm{Xhol}$ ) are added to a microtube at the same time.

\section{Ligation}

Ligation of $\mathrm{Ncol} / \mathrm{Xhol}$ double-digested plasmids was carried out in the same microtube. $1 \mu \mathrm{L}$ ligase $(10$ $\mathrm{u}$ ) and $1 \mu \mathrm{L}$ of its $10 \mathrm{X}$ buffer were added to the microtube, which then incubated at room temperature for another $1 \mathrm{~h}$. After this period, ligase was inactivated by $15 \mathrm{~min}$ incubation at $65^{\circ} \mathrm{C}$ and the ligation product was precipitated in the same way as already described. The precipitant was re-solubilized in $10 \mu \mathrm{LWW}$.

\section{Simultaneous digestion of ligation product with Hind III- the second round of digestion}

Intact $\mathrm{pET} 22 \mathrm{~b}(+)$ contains several sites for restriction enzymes, including Ncol, BamHI, EcoRI, Sacl, Sall, HidllI, Notl, and Xhol. So, all the restriction sites between Ncol and Xhol would be absent in recombinant $\mathrm{pET} 22 \mathrm{~b}(+)$ if the insert be devoid of these restriction sites. The scFv gene used in this study contains an EcoRI restriction site in its sequence between $\mathrm{Ncol}$ and Xhol restriction, so we did not consider this enzyme for the second round of digestion. Among the enzymes listed above, we used Hind III to digest unwanted plasmid constructs. $1 \mu \mathrm{L}$ of the enzyme in company with $1.2 \mu \mathrm{L}$ of its $10 \mathrm{X}$ buffer was added to the microtube (containing $10 \mu \mathrm{L}$ ligation product prepared in previous stage) and allowed to digest the ligation product for $1 \mathrm{~h}$ at $25^{\circ} \mathrm{C} .5 \mu \mathrm{L}$ of the final solution was used to transform competent DH5- Alpha bacterial cells.

\section{Double digestion for truncation of a nucleotide sequence}

There are lots of engineered plasmids whose nucleotide sequences encode for fusion proteins [e.g. proteins fused to nuclear localization signals (NLS) or cell penetrating peptides] or multi-domain proteins. If the nucleotide sequence encoding for a protein subunit is flanked by an enzyme restriction site, it would be easily cut out of the plasmid. The in-situ digestion-ligation gel-free method described in this study (Figure 2) will be also useful for truncation of such multi- subunit genes. Using this method, we cut out NLS-encoding sequences form Herceptin $\mathrm{VH}-(\mathrm{NLS})_{4}$ fusion protein- encoding sequence. pET22b(+)-Herceptin VH-(NLS) 4 recombinant plasmid (150 ng) was digested using Hind III restriction enzyme within a $250 \mu \mathrm{L}$ microtube and precipitated in the same way as described $\mathrm{Ncol} / \mathrm{Xhol}$ double digested plasmids. The precipitant was dissolved in $8 \mu \mathrm{L} \mathrm{DW}$ and subjected to ligation reaction by addition of $1 \mu \mathrm{L} \mathrm{T4} \mathrm{DNA} \mathrm{ligase} \mathrm{and} 1 \mu \mathrm{L}$ of its $10 \mathrm{X}$ buffer. 5 $\mu \mathrm{L}$ of the solution was used to transform competent $E$. coli cells. Similarly, we cut "C-terminal signal peptideencoding segment" out from "pET22b(+)-Cetuximab VH- C. terminal signal peptide" recombinant plasmid using Hind III whose restriction site flanks the segment. Precipitation and ligation stages were carried out in the same way as described for pET22b (+)-Herceptin VH-(NLS) $)_{4}$ plasmid. 

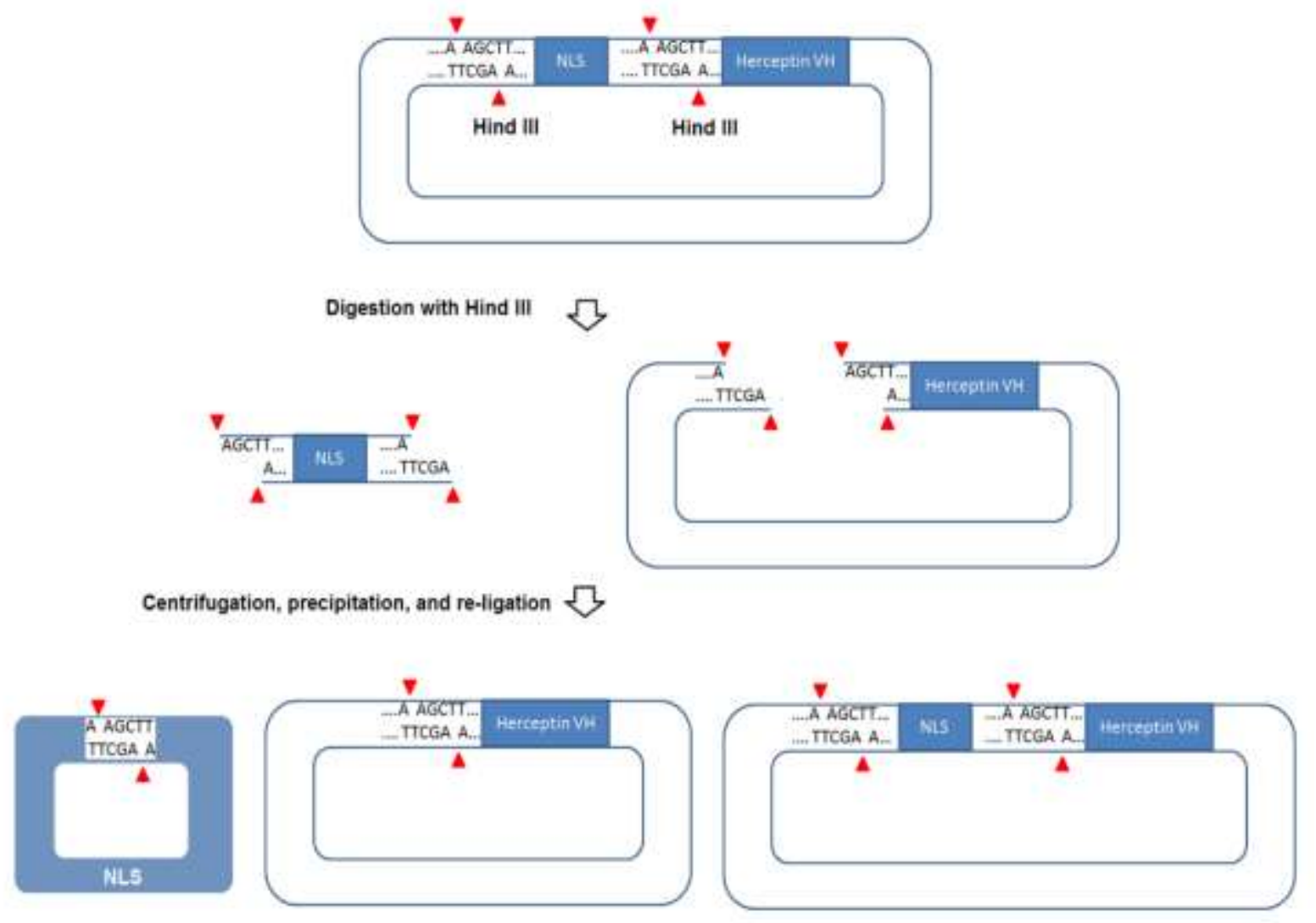

Figure 2. In-situ double digestion of Herceptin VH-(NLS) $)_{4}$ encoding plasmid using Hind III for gene truncation. Hind III double digestion results in formation of two DNA molecules, (NLS) ${ }_{2}$-containing fragment and a linearized plasmid containing Herceptin $\mathrm{VH}-(\mathrm{NLS})_{2}$. Re-ligation of this mixture may result in formation of three types of circular DNA molecules. Circular NLS does not contain Ori sequence and therefore will be degraded in bacterial cytoplasm.

\section{Colony PCR}

Colony PCR was carried out to analyze the digestion-ligation products. Bacterial colonies were suspended in $50 \mu \mathrm{L}$ distilled water and boiled for 5 min to release their plasmids. $2 \mu \mathrm{L}$ of the prepared solution of each colony was added to a microtube containing $1 \mu \mathrm{L}$ forward primer, $1 \mu \mathrm{L}$ reverse primer, $10 \mu \mathrm{L}$ of $2 \mathrm{X}$ PCR master mix, and $6 \mu \mathrm{L}$ distilled water (DW). PCR was done for 30 cycles at the condition described in Table 1.

Table 1. Temperature and time table of colony PCRstages

\begin{tabular}{clcc}
\hline Cycle (s) & \multicolumn{1}{c}{ Step } & Temperature & Time \\
\hline 1 & Initial denaturation & $94{ }^{\circ} \mathrm{C}$ & $1 \mathrm{~min}$ \\
\hline \multirow{3}{*}{30} & Denaturation & $94{ }^{\circ} \mathrm{C}$ & $1 \mathrm{~min}$ \\
\cline { 2 - 4 } & Annealing & $51{ }^{\circ} \mathrm{C}$ & $45 \mathrm{~s}$ \\
\cline { 2 - 4 } & Extension & $72{ }^{\circ} \mathrm{C}$ & $1 \mathrm{~min}$ \\
\hline 1 & Final extension & $72{ }^{\circ} \mathrm{C}$ & $5 \mathrm{~min}$ \\
\hline
\end{tabular}

\section{RESULTS}

Simultaneous digestion of $\mathrm{pGH}-\mathrm{scFv}$ and empty $\mathrm{pET} 22 \mathrm{~b}(+)$ vectors in a single microtube and subsequent ligation of digested DNA molecules gives rise to four potential plasmid constructs, one of which is recombinant $\mathrm{pET} 22 \mathrm{~b}(+)$ containing our gene of interest (Figure 3 ). 

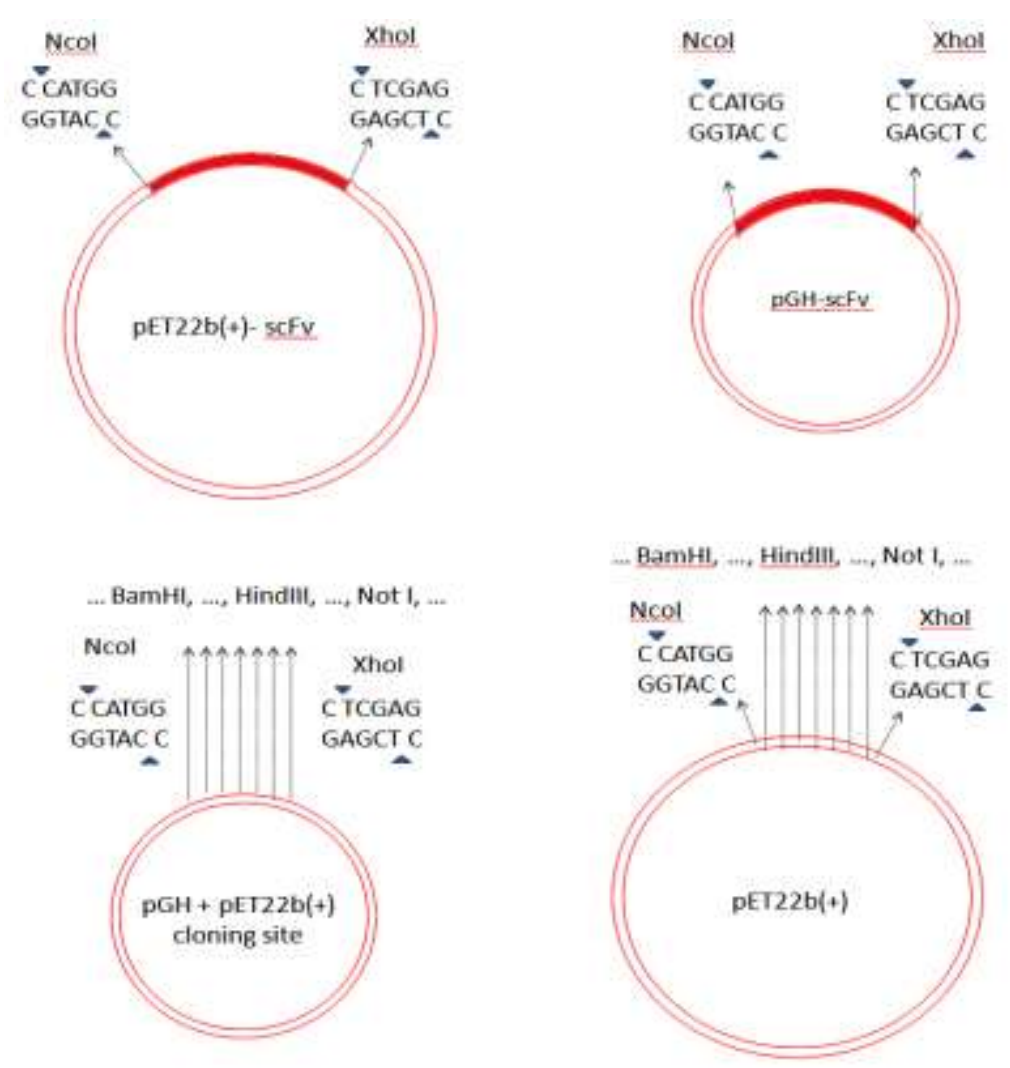

Figure 3. Potential plasmid constructs following Ncol/Xhol double digestion, centrifugation, and re-ligation of digestion products. (A) The gene of interest may exit pGH and enter pET22b(+) expression vector. (B) The gene of interest may re-conjugate to $\mathrm{pGH}$. (C): Cloning region of $\mathrm{pET} 22 \mathrm{~b}(+)$ which carries the $\mathrm{Ncol} / \mathrm{Xhol}$ sticky ends enters Ncol/Xhol double digested pGH. (D): Cloning region of $\mathrm{pET} 22 \mathrm{~b}(+)$ may re-conjugate to $\mathrm{Ncol} / \mathrm{Xhol}$ double digested $\mathrm{pET} 22 \mathrm{~b}(+)$, making an re-assembled full-length plasmid.

Hind III restriction enzyme used in the second round of digestion makes a nick in the plasmids that carry at least one restriction site for this enzyme. So, re-assembled pET22b(+) and recombinant pGH $[\mathrm{pGH}$ containing cloning site of $\mathrm{pET} 22 \mathrm{~b}(+)$ ] plasmids are exposed to Hind III digestion. Linear plasmids are degraded in the cytoplasm and therefore their host would not survive on selective culture medium. Transformation of Hind III-treated plasmid constructs into E. coli DH5-Alpha cells resulted in formation of 44 bacterial colonies on Amp+ LB medium, 19 of which were randomly selected for analysis by colony PCR.

4 out of the 19 colonies were identified to be pET22b(+)-scFv (lanes D, M, U and V) (Figure 4). To insure that the colonies were identified correctly, two clones were tested again and confirmed to have recombinant $\mathrm{pET} 22 \mathrm{~b}(+)$. Since the primers do not match with the strands $\mathrm{pGH}$ cloning vector, the negative colonies should be of pGH nature, recombinant pGH [pGH containing cloning site of pET22b(+)] or re-assembled pGH. The first contains a Hind III restriction site in its sequence (Figure 3) and therefore it should be sensitive to Hind III digestion, meaning that it does not contribute to colony formation.

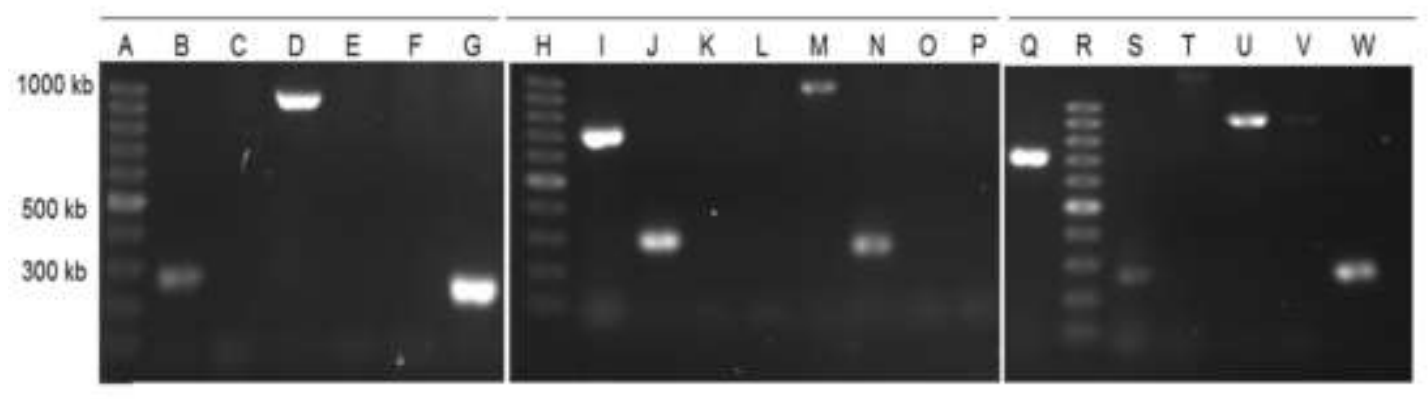

Figure 4. Colony PCR with $\mathrm{pET} 22 \mathrm{~b}(+)$ specific primer pair for selection of bacterial colonies hosting scFv gene. Lanes A, H, and R: 100 bp DNA ladder. Lanes B, J, N, S and W: the size of PCR products indicates that the colonies contain empty pET22b(+) vector. Lane G: empty pET22b(+) vector (control). The primers replicate a 298 bp segment, extending from T-7 promoter region to T-7 terminator region. Lanes $D, M, U$ and $V$ : recombinant $p E T 22 b(+)$-scFv. DNA bands of $973 \mathrm{bp}$ appear in these lanes. Lanes I and Q: unknown. Lanes C, E, F, K, L, O, P and T: the bacterial colonies should contain $\mathrm{pGH}$ vector since the $\mathrm{pET} 22 \mathrm{~b}(+)$ specific primers do not recognize $\mathrm{pGH}$ strands. 


\section{Truncated plasmids}

We expected to have DNA bands of 889 and $760 \mathrm{bp}$ in PCR products of Herceptin VH-(NLS) 4 and Herceptin VH-(NLS) $)_{2}$, respectively. We tested 8 bacterial colonies using PCR colony, 6 of which were found to be Herceptin $\mathrm{VH}-(\mathrm{NLS})_{2}$ (Figure 5-A). We also tested the method for truncation of "Cetuximab $\mathrm{VH}$ C.terminal signal peptide fusion protein" encoding plasmid (schematic overview not shown). We examined eight bacterial colonies using colony PCR. The colonies all produced a DNA band of $613 \mathrm{bp}$ in PCR (Figure $5-B)$, indicating that the nucleotide sequence encoding for $C$. terminal signal peptide ( $210 \mathrm{bp}$ ) has been removed from the whole plasmid, which produces a DNA band of $823 \mathrm{bp}$ in PCR.

A

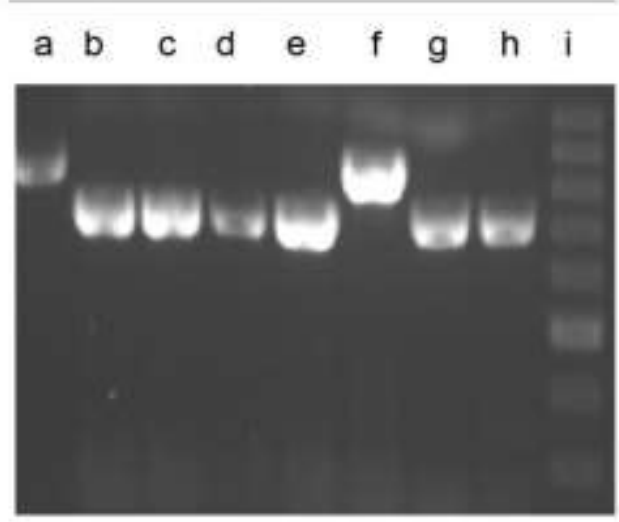

B

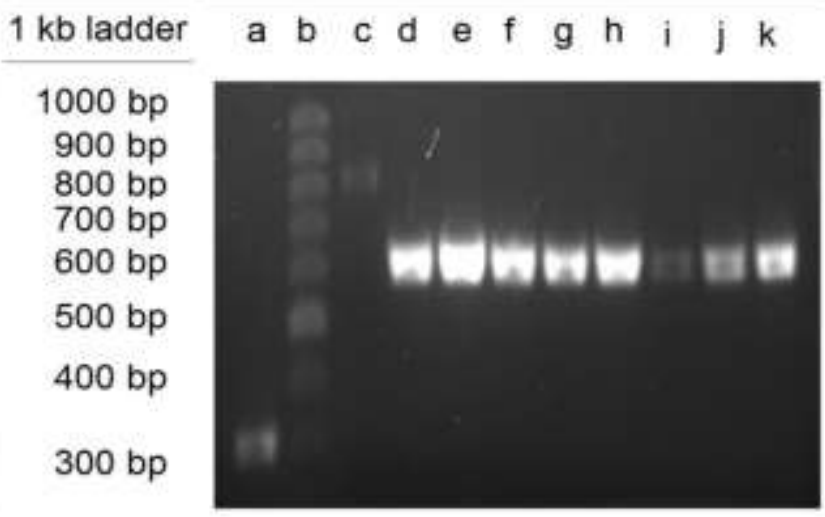

Figure 5. Colony PCR for identification of bacterial colonies hosting plasmids of interest. (A) line "a" indicates the control vector, (pET22b(+)-Herceptin VH-(NLS)4. 6 colonies (b, c, d, e, g and h) were found to contain pET22b(+)-Herceptin $\mathrm{VH}-(\mathrm{NLS})_{2}$ vector, which produces a DNA band of $760 \mathrm{bp}$ in PCR. One colony (f) was found to contain intact plasmids, which produces DNA bands of $889 \mathrm{bp}$ using pET22b(+) specific primer pair. Appearance of this band indicate that a number of $(\mathrm{pET} 22 \mathrm{~b}(+)$-Herceptin $\mathrm{VH}-(\mathrm{NLS}) 4$ vectors remains intact during incubation with Hind III. (B) Colony PCR of E. coli BL21 (DE3) cells transformed with in-situ double-digested "pET22b(+)-Cetuximab VH-C.terminal signal peptide" vector. All the eight colonies tested (c-I) were found to have a 210 bp deletion (C.terminal signal peptide encoding segment) when compared to parental undigested vector, which produces a DNA band of 833 bp in PCR (b).

\section{DISCUSSION}

In the current study, we introduced a gel-free in-situ method for subcloning and truncation of nucleotide sequences of interest. In regular subcloning procedures, the molar ratio of insert: plasmid is often adjusted to $1: 1$ to 10:1 [7]. When the same number of two circular plasmids are mixed together in a microtube and subjected to simultaneous digestion, this ration is about 1:1. As shown in Figure 2, four different types of plasmids are expected to form when two plasmids are mixed and digested. Since we used Hind III restriction enzyme in the second round of digestion, we did not expect to have bacterial colonies hosting re-assembled $\mathrm{pET} 22 \mathrm{~b}(+)$. Emergence of a bacterial colony hosting empty $\mathrm{pET} 22 \mathrm{~b}(+)$ vector (Figure 3 ) indicates that a number re-assembled $\mathrm{pET} 22 \mathrm{~b}(+)$ plasmids have not been digested by Hind III, while carrying Hind III restriction site in their sequence. Presence of a number of undigested plasmids in digestion mixture is not surprising; they may occur even in a good digestion [8]. When a circular plasmid is double-digested with a single enzyme, two DNA molecules with identical sticky ends are formed (Figure 4). In this condition, two independent ligations between the linearized plasmid and the released segment are required to obtain the original plasmids. While, each of the DNA molecules can form a circular molecule by only one ligation reaction. It may justify why the majority of bacterial colonies host truncated plasmids rather that re-assembled full-length plasmids.

\section{CONCLUSION}

Parental cloning vector and the expression vector to which the gene of interest is going to be inserted can be mixed and subjected to defined restriction enzymes to exchange nucleotide sequences standing between the restriction sites. Bacterial colonies containing the recombinant expression plasmid of interest can be identified using colony PCR. Plasmids encoding for multi-subunit proteins can be easily truncated by the gel-free method described in this study if the nucleotide sequence encoding for a subunit is flanked by specific restriction site of a restriction enzyme. In such condition, truncated plasmid can be obtained by insitu digestion and re-ligation of the digestion product in a single microtube. The method is reliable, easy, and time consuming. 
Funding: The fund for this project was provided from four independent research projects supported by Golestan University of Medical Sciences (Gorgan, Iran): Project 1: approval codes of 941120261; Project 2: approval code of 110235 (with ethics approval code of IR.GOUMS.REC.1397.236); Project 3: approval code of 110172 (with ethics approval code of IR.GOUMS.REC.1397.270); Project 4: approval code of 110121 (with ethics code of IR.GOUMS.REC.1398.001).

Acknowledgements: The authors thank Dr. Abolfazl Amini for his technical supports.

Conflicts of interests: There are no conflicts of interests to declare.

\section{REFERENCES}

1. Lopez CA, Nakamori M, Thornton CA, Pearson CE. Identification of restriction endonucleases sensitive to 5cytosine methylation at non-CpG sites, including expanded (CAG)n/(CTG)n repeats. Epigenetics. 2011 Apr;6 (4):416-20.

2. Marinus MG, Lobner-Olesen A. DNA Methylation. EcoSal Plus. 2014 May;6(1):10.1128/ecosalplus.ESP-00032013.

3. Palmer BR, Marinus MG. The dam and dcm strains of Escherichia coli-a review. Gene. 1994 May;143(1):1-12.

4. Rumora AE, Kolodziejczak KM, Malhowski WA, Nunez ME. Thymine dimer-induced structural changes to the DNA duplex examined with Reactive probes. Biochemistry.2008 Dec;47(49):13026-13035.

5. Schreier WJ, Schrader TE, Koller FO, et al. Thymine dimerization in DNA is an ultrafast Photoreaction. Science. 2007 Feb;315(5812):625-629.

6. Tips for Maximizing Ligation Efficiencies. New England Biolabs, Inc (NEB); updated 2020 Jan. Available from: https://international.neb.com/tools-and-resources/usage-guidelines/tips-for-maximizing-ligation-efficiencies.

7. 5 Tips on Vector Preparation for Gene Cloning. 2007 Aug 22; [updated 2016 Apr 29]. Available from: https://bitesizebio.com/13500/cloning-tips-vector-prep/.

(C) 2020 by the authors. Submitted for possible open access publication under the terms and conditions of the Creative Commons Attribution (CC BY NC) license (https://creativecommons.org/licenses/by-nc/4.0/). 